\title{
CLASSIFICAÇÃO PELO MÉTODO K-MÉDIAS DAS BACIAS DE DRENAGEM DO RIO IPANEMA (AL/PE) CONSIDERANDO OS ATRIBUTOS MORFOMÉTRICOS
}

\section{CLASSIFICATION USING K-MEANS METHOD IN DRAINAGE BASINS OF IPANEMA RIVER (AL/PE) CONSIDERING THE MORPHOMETRIC ATTRIBUTES}

\author{
Aline Brignol Menke \\ Mestre em Geografia \\ UNB \\ alinemenke@gmail.com \\ Osmar Abílio Carvalho Júnior \\ Doutor em Geologia \\ UNB \\ osmarjr@unb.br \\ Renato Fontes Guimarães \\ Doutor em Geologia \\ UNB \\ renatofg@unb.br \\ Roberto Arnaldo Trancoso Gomes \\ Doutor em Geografia \\ UNB \\ robertogomes@unb.br \\ Sandro Nunes de Oliveira \\ Doutorando em Geografia \\ UNB \\ sandronunes@unb.br
}

\section{Resumo:}

A compartimentação geomorfológica vem sendo amplamente utilizada para a identificação de geoambientes caracterizando-se como um instrumento fundamental para auxílio à gestão do território. Uma das maneiras de se obter compartimentos é a partir de bacias hidrográficas, visto que os cursos d'água possuem importante papel na modelagem do relevo. Dentro deste contexto, esse trabalho tem como objetivo definir unidades geomorfológicas utilizando análise de grupos pelo método K-médias em bacias hidrográficas de primeira ordem na Bacia do Rio Ipanema (PE/AL).A metodologia se constitui das seguintes etapas: a) Confecção do MDT hidrologicamente correto e dos atributos de terreno, b) Delimitação das bacias de drenagem de $1^{\mathrm{a}}$ ordem e o cálculo das variáveis morfométricas e c)Classificação das bacias de drenagem utilizando o método K-Médias. As classes foram utilizadas para definir as unidades geomorfológicas da bacia definidas como:Planalto da Borborema; Rebordos Escarpados 
e Elevações Residuais; Pediplano do Baixo São Francisco; e Depressão do São Francisco.

Palavras-Chave: morfometria; compartimentação geomorfológica; bacia hidrográfica; análise de grupos; K-médias.

\begin{abstract}
:
The geomorphological unit has been widely used for identifying homogeneous landscape over important to land management. This is can be obtained by Watershed because the waterways play an important role in modeling landscape. Within this context, this study aims to define geomorphological units using cluster analysis by kmeans method in first-order watersheds in the Ipanemariveebasin (PE / AL). The methodology is constituted of the following steps: a) Elaboration of the DTMhydrologically correct and the morphometric attributes, b) 1st order watershed delineation and the calculation of morphometric variables and c) Classification of drainage basins using K-Means method. The classes wereusedto define thegeomorphologicalunitsofthebasindefinedas:Planalto da Borborema; Rebordos Escarpados e Elevações Residuais; Pediplano do Baixo São Francisco; e Depressão do São Francisco.
\end{abstract}

Keywords: morphometry; geomorphological unit; basins; cluster analysis; K-means.

\title{
INTRODUÇÃO
}

A necessidade do aumento de produção e da acomodação da população tem provocado mudanças e conflitos no uso da terra, determinando a necessidade de se identificar estratégias e diretrizes que equilibrem os diferentes interesses que regem a ocupação do espaço. O elevado crescimento demográfico, a expansão desordenada da malha urbana; a escassez das terras férteis e a degradação dos recursos hídricos, entre outros, requerem a existência de estudos que permitam orientar a ocupação do território de forma a manter o equilíbrio entre os processos naturais e a ação antrópica. Desta forma, procura-se aproveitar a aptidão natural das terras de forma a obter um melhor desempenho socioeconômico sem que haja degradação intensiva dos recursos naturais. Para tanto, deve-se compreender as limitações e potencialidades físicas do ambiente construindo cenários futuros e buscando uma racionalização adequada do meio físico.

Os estudos em bacias hidrográficas permitem fazer planejamentos de longo prazo que equilibrem a demanda com a capacidade de suporte do sistema ambiental. Desta forma, a bacia hidrográfica é a unidade territorial mais utilizada em estudos 
ambientais, pois representa parte das relações de causa-efeito presentes no meio ambiente. As configurações espaciais das bacias de drenagem são modeladas pela difusão e incisão dos processos erosivos de forma a minimizar a perda de energia (AB'SABER, 2005; LANGBEIN e LEOPOLD, 1964; MONTGOMERY e DIETRICH, 1994). Portanto, conhecer as feições e os padrões do terreno que compõe uma bacia hidrográfica permite inferir sobre os fatores e os processos nela atuantes.

As bacias de drenagem podem ser delimitadas utilizando técnicas manuais ou automatizadas. A evolução e o aprimoramento das técnicas computacionais permitem as seguintes vantagens em relação às técnicas manuais: maior rapidez, menor subjetividade, maior facilidade de reprodução,diminuição de custos e de tempo. Neste propósito as técnicas presentes em Sistema de Informações Geográficas (SIG) permitem um grande avanço na extração de informações hidrográficas e geomorfológicas a partir de Modelos Digitais de Terreno (MDT),possibilitando maior precisão na obtenção de atributos, como:redes hidrográficas; bacias e sub-bacias de drenagem e atributos de terreno.

Diferentes atributos morfométricos das bacias e sub-baciassão propostos para a distinção de processos naturais, como: hidrologia, sedimentação, erosão, enchentes, movimento de massa, evolução pedológica, entre outros (REDDY et al., 2004; VILLELA e MATTOS, 1975; CARDOSO et al., 2006; DEMATTÊ e DEMÉTRIO, 1995; MESA, 2006; SOUZA e BATISTA, 2007).Além disso, a análise estatística multivariada das informações morfométricas permite individualizar e classificar diferentes ambientes e paisagens(GILES e FRANKLIN, 1998; MILIARESIS e ARGIALAS, 1999, OLIVEIRA et al., 2007, SODRÉ et al, 2007).

O objetivo deste trabalho é definir unidades geomorfológicas utilizando análise de grupos pelo método K-médias em bacias hidrográficas de primeira ordem na Bacia do Rio Ipanema (PE/AL).

A bacia do Rio Ipanema está localizada entre a porção meridional do Estado de Pernambuco e a porção norte do Estado do Alagoas (Figura 1). Esta pertence à bacia hidrográfica do Rio São Francisco com uma área aproximada de $7.763 \mathrm{~km}^{2}$. Nesta 
localidade o clima predominante é o tropical seco do tipo Bsh, segundo a classificação de Köppen.

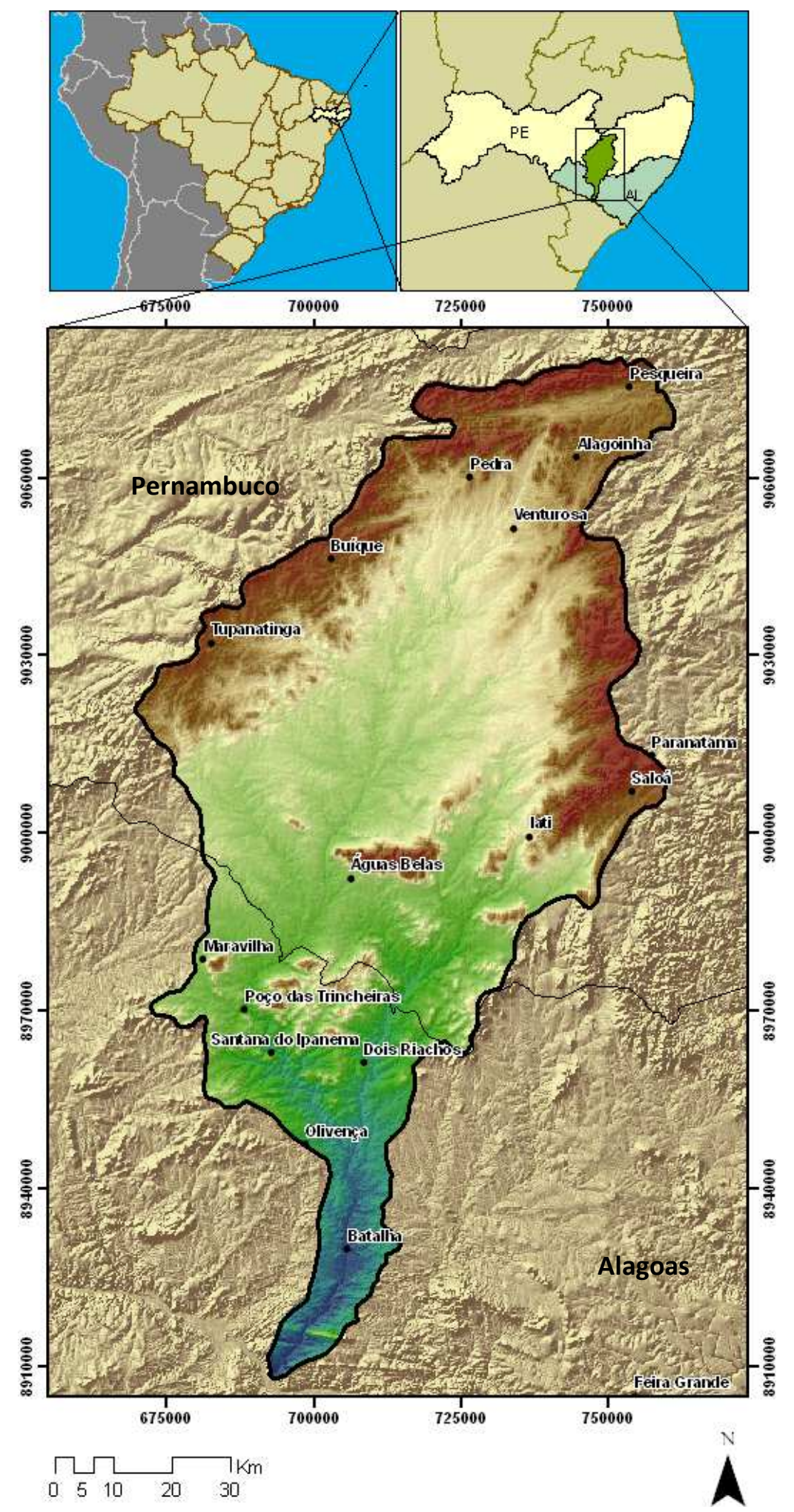

Figura 1. Mapa de localização da área de estudo.

Geo UERJ - Ano 15, n'. 24, v. 2, $2^{\circ}$ semestre de 2013 ISSN: 1415-7543E-ISSN: 1981-9021

http://www.e-publicacoes.uerj.br/index.php/geouerj 
A bacia do Rio Ipanema é formada na sua parte superior por superfícies entalhadas do cristalino que, passando para altitudes menores, despontam maciços de serras baixas até atingir a depressão do rio São Francisco, no estado do Alagoas. O embasamento cristalino que forma o Planalto da Borborema, pertencente às Províncias do Escudo Atlântico, representa uma abrangente zona de desenvolvimento geológico Pré-Cambriano do Nordeste. A maior parte da área é coberta pelo Complexo GranitoGnaissico apresentando no topo Metadiorito, Metagranito e Metamonzodiorito. No oeste da bacia aparecem Granodiorito, Anfibolito, Mármore, Migmatito e Leucogranito (CPRM, 2004). As colinas características das depressões interplanálticas em Pernambuco possuem baixo grau de intemperismo químico e estão assentadas sob xistos e gnaisses. Os inselbergs oriundos do final do terciário e início do quaternário (AB'SABER, 2005), resistem devido ao granito e as lentes de quartzito.

\section{METODOLOGIA}

A metodologia utilizada pode ser subdividida nas seguintes etapas: (a) confecção do MDT hidrologicamente correto e dos atributos de terreno, (b) delimitação das bacias de drenagem de primeira ordem e aplicação de estatísticas zonais com base nas áreas de bacias; e (c) análise de clusters nas bacias de drenagem utilizando o método K-médias.

\section{a.Confecção do MDT hidrologicamente correto e dos atributos de terreno}

A delimitação automatizada das bacias hidrográficas requer a elaboração de um MDT hidrologicamente correto. Este modelo pode ser obtido a partir das seguintes etapas: (a) geração de um MDT prévio; (b) aprofundamento dos canais de drenagem; e (c) geração do MDT com direção de fluxo corrigida (Figura 2).

Na elaboração do MDT prévio foram utilizadas as cartas topográficas na escala de 1:100.000 obtidas junto à Companhia de Desenvolvimento do Vale do São Francisco e do Parnaíba (CODEVASF). Os vetores de hipsometria, pontos cotados e hidrografia passaram por correções topológicas, eliminando as descontinuidades e as informações inconsistentes. Os vetores de hidrografia tiveram o direcionamento de fluxo ajustados corretamente. O método de interpolação utilizado na elaboração do MDT foi o Topogrid (HUTCHINSON, 1989), apropriado para estudos hidrológicos. Este método utiliza a interpolação por diferenças finitas que preserva as características hidrográficas 
(JENSON e DOMINIQUE, 1988). Para a área de estudo foi gerado um MDT com resolução espacial de 40 metros.

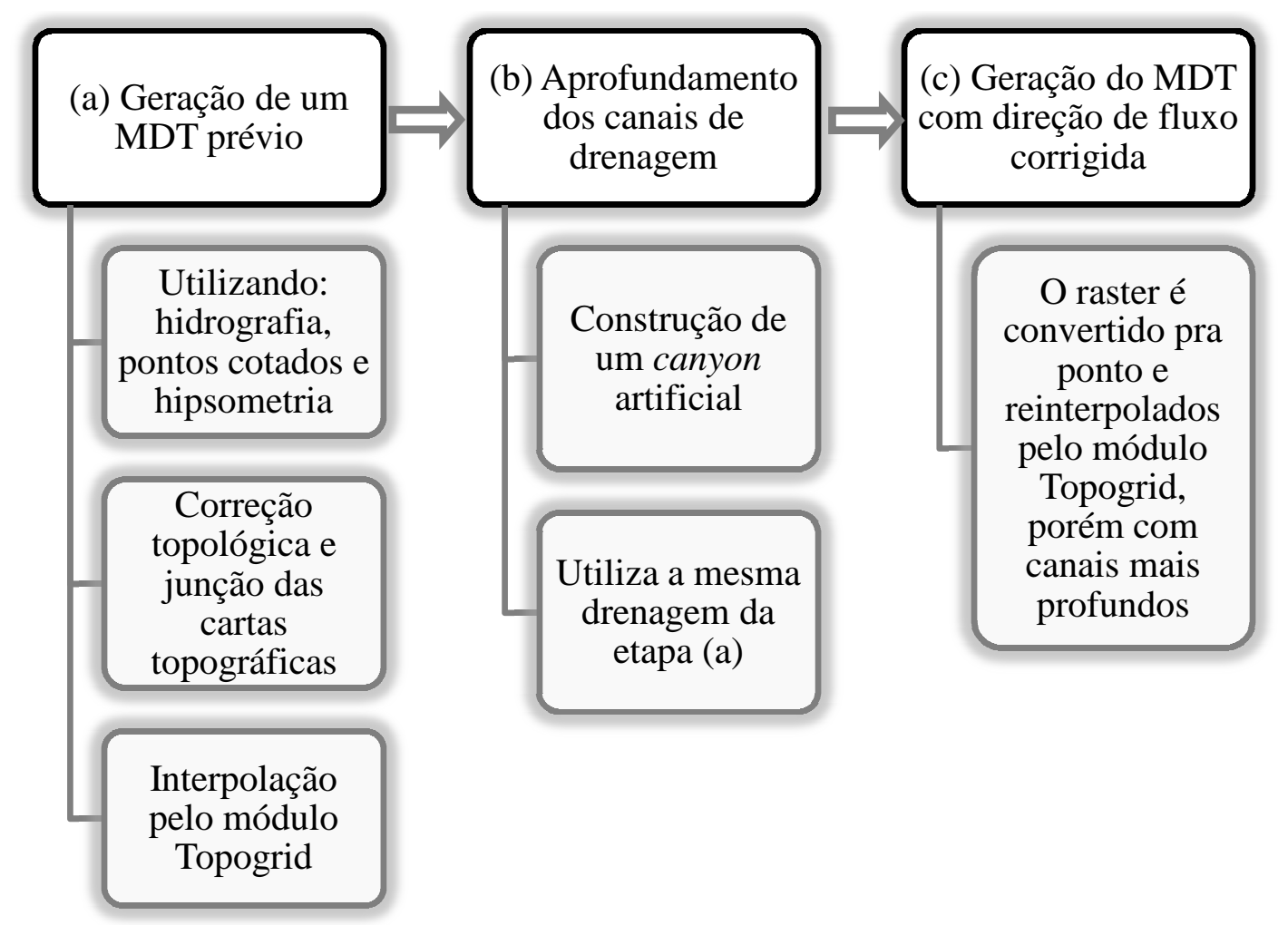

Figura 2.Fluxograma da geração do MDT com aprofundamento de canal.

No entanto, nas áreas aplainadas persistiram erros devido à falta de informações entre as curvas de nível, que impedem o entalhamento correto da hidrografia (Figura 3). Estes erros podem impedir uma correta delimitação automática das bacias de drenagens. Com o propósito de corrigir este erro e forçar o estabelecimento de um fluxo correto realizou-se o aprofundamento da rede de drenagem, gerando formas similares a canyons artificiais. A álgebra de mapas para o aprofundamento da drenagem pode ser obtida pelo somatório de dois MDTs (Figura 4) (OLIVEIRA et al., 2007): rede de drenagem com grade binária nula (A) e a rede com valor 1 (um) (A1); MDT do canal de drenagem com valores altimétricos subtraídos de 30 metros (B) e MDT sem rebaixamento. O resultado da multiplicação de A por B, é uma grade com valores de altimetria apenas nos canais de drenagem (C) e a multiplcação de A1 por B1 tem como resultado uma grade de valores altimétricos apenas no interflúvio. O resultado da combinação é um MDT com a drenagem aprofundada artificialmente em 30 metros. 


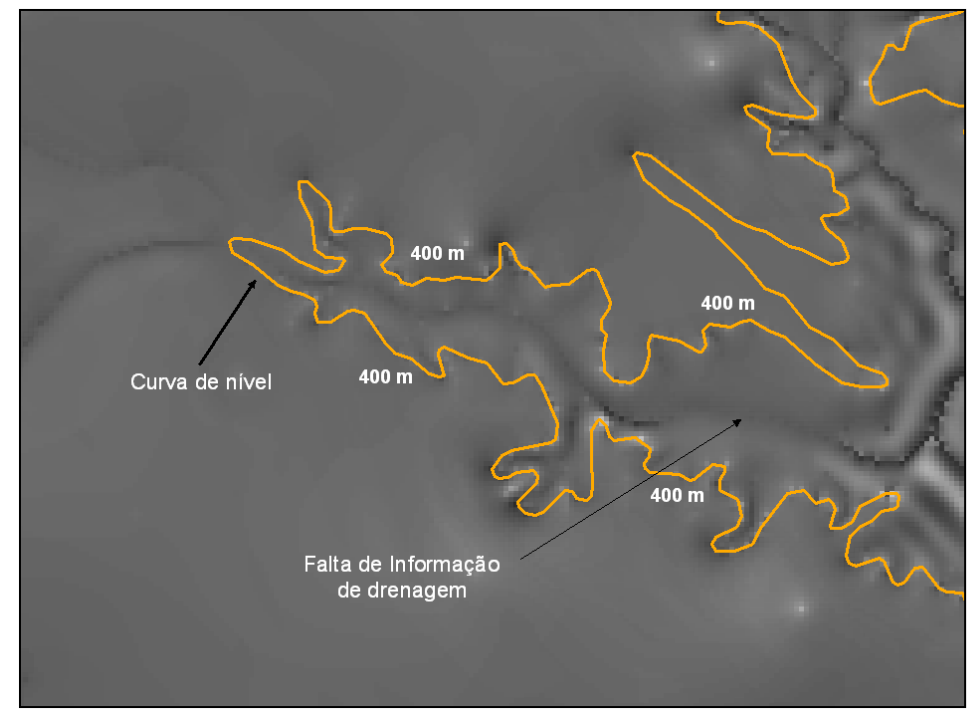

Figura 3. Erros presentes no MDT em áreas planas.
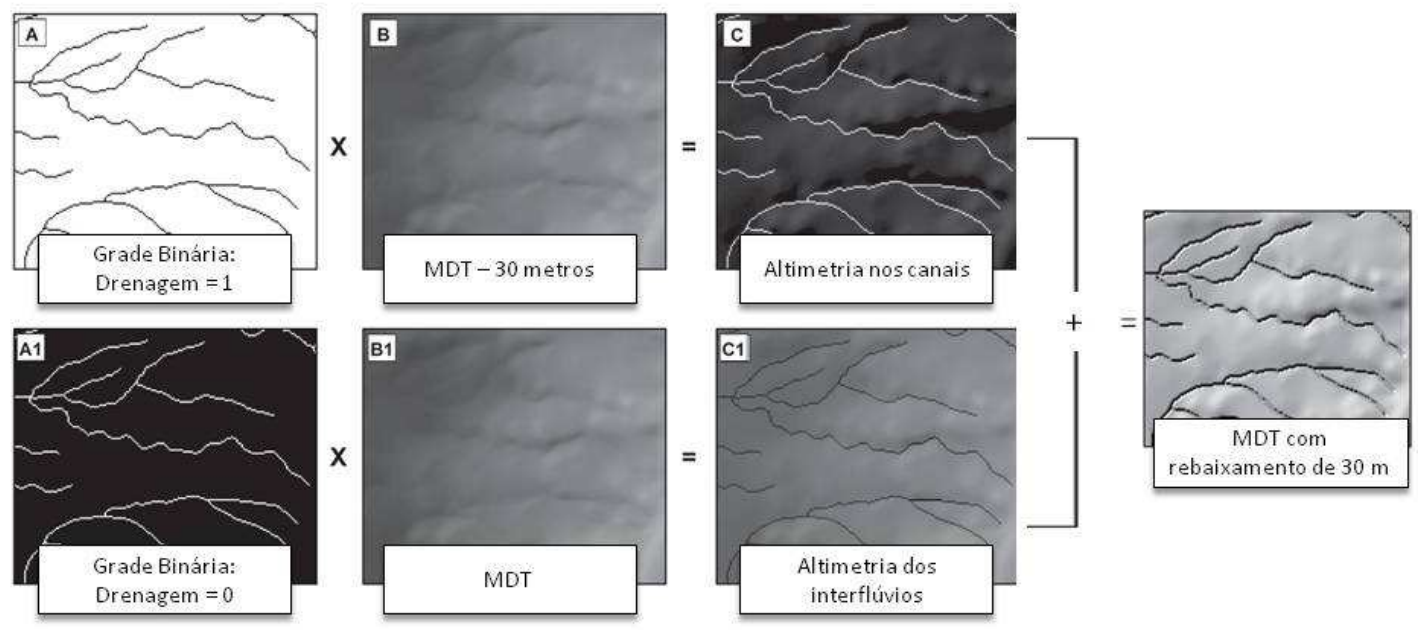

Figura 4. Operação para aprofundamento dos canais de drenagem. Modificado de Sodré, 2007.

Com o aprofundamento da drenagem realiza-se o preenchimento de pequenas depressões circulares e o cálculo da direção de fluxo pelo método D8 proposto por O’Callaghane Mark (1984). Esta metodologia mantém a conectividade do fluxo ao longo do canal estabelecendo uma relação unimodal da direção do fluxo ao longo da rede de drenagem. Essa característica é desejável para a rede de drenagem, cujo fluxo migra, necessariamente, para uma das oito direções, não se dissipando. Para as demais áreas fora dos canais pode-se utilizar o método D-infinito proposto por Tarboton (1997), 
que permite uma melhor simulação da realidade por ser multimodal. Desta forma, conjugam-se os dois modelos de fluxo: D-8 para as áreas ao longo dos canais e Dinfinito para as demais áreas. A individualização dos modelos de fluxo pode ser obtida pelo emprego de máscaras binárias relativas à rede de drenagem (TARBOTON, 2005).A Figura 5 apresenta os atributos de terreno, relativos à declividade e a área de contribuição.
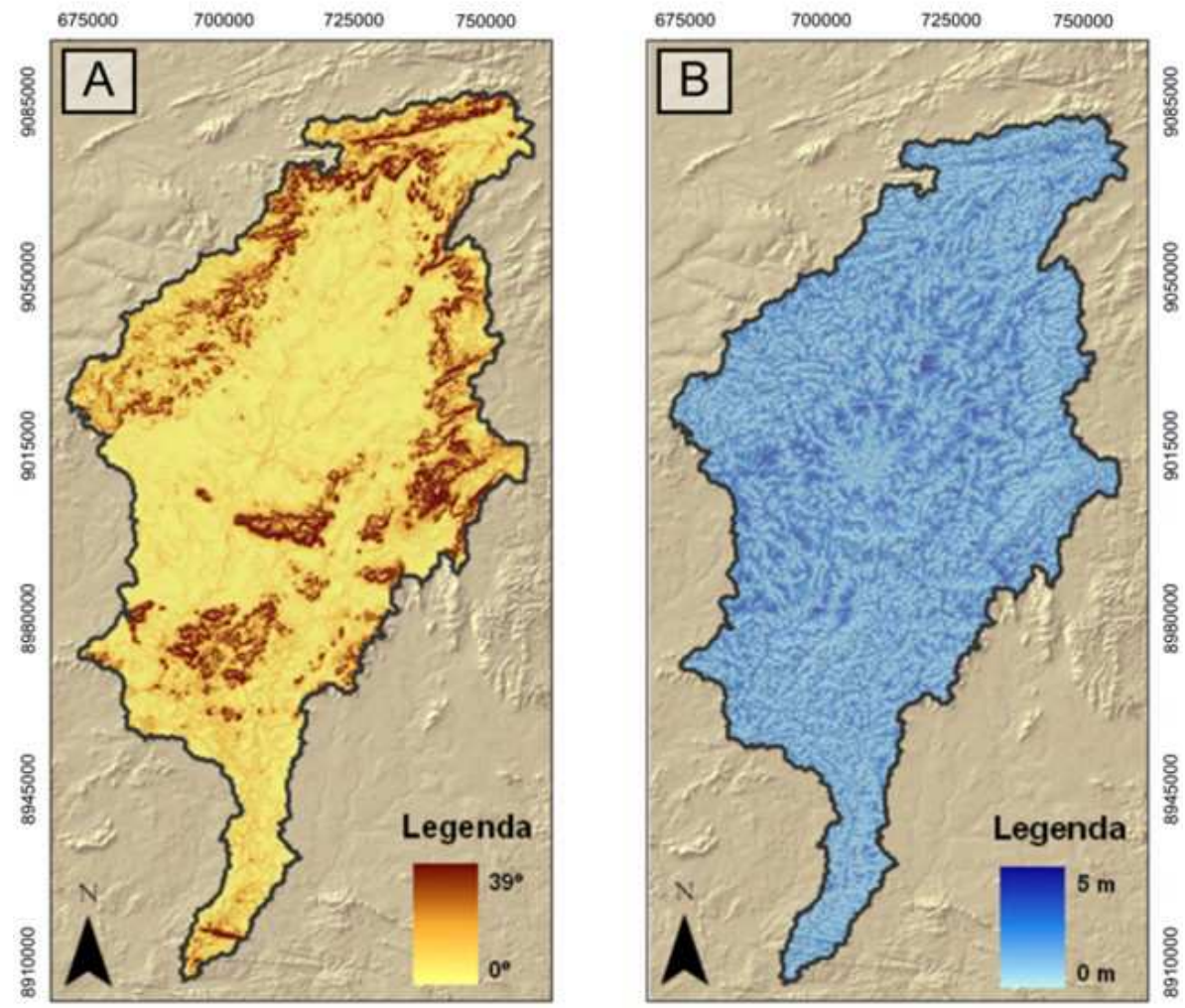

Figura 5. Declividade (a) e Área de Contribuição (b) da bacia do Rio Ipanema.

\section{b.Delimitação das bacias de drenagem de $1^{\text {a }}$ ordeme 0 cálculo das variáveis morfométricas}

A delimitação das bacias de primeira ordem conforme a hierarquização fluvial de Strahler (STRAHLER, 1952) foi obtida pela utilização do algoritmo Taudem (Terrain Analysis Using Digital Elevation Models)(TARBOTON, 2008).As bacias são delimitadas com base nas informações de direção de fluxo e de área de contribuição. As bacias encontradas obedecem aos parâmetros topográficos, em que as linhas divisórias Geo UERJ - Ano 15, n'. 24, v. 2, $2^{\circ}$ semestre de 2013 ISSN: 1415-7543E-ISSN: 1981-9021

http://www.e-publicacoes.uerj.br/index.php/geouerj 
passam pelos pontos mais elevados do relevo chegando até o exutório do rio. A utilização da ferramenta Taudem permite a delimitação das bacias de $1^{\mathrm{a}}$ ordem, como também, fragmentos de bacia demarcados entre o exutório de duas bacias de mesma ordem (Figura 6). Assim, a delimitação das bacias hidrográficas de primeira ordem mais os fragmentos permitiram individualizar os compartimentos que possuem correspondência com a superfície permitindo o entendimento das formas e processos que predominam na bacia do rio Ipanema.
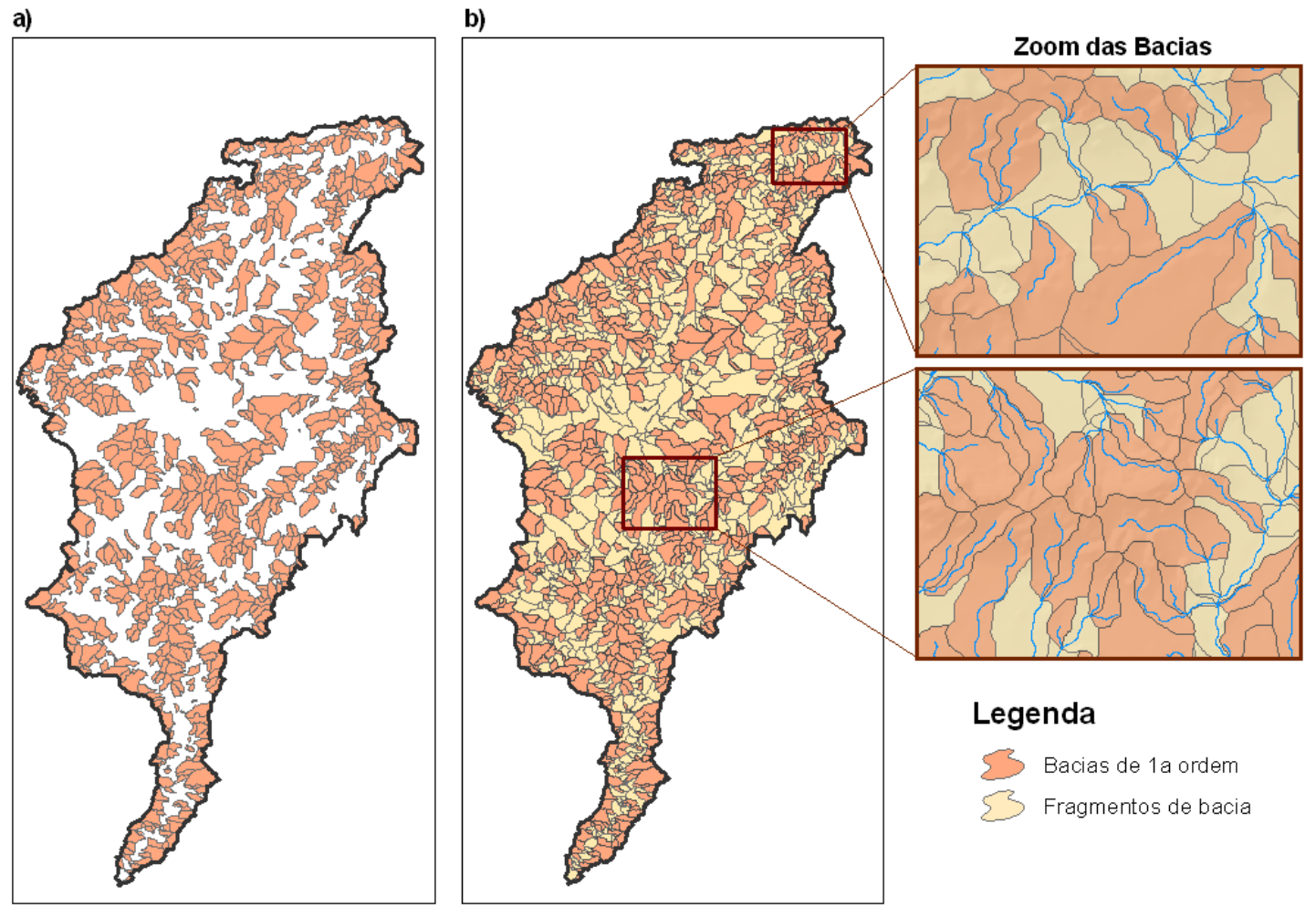

Figura 6. Delimitação das bacias de drenagem de $1^{a}$ ordem; (b) bacias de primeira ordem mais fragmentos.

A partir doMDT, declividade e área de contribuição foram calculados valores para as bacias hidrográficas utilizando a análise zonal, que quantificou os seguintes atributos de terrenos para cada bacia:altitude máxima (Figura 7a);altitude mínima (Figura 7b);altitude média (Figura 7c); amplitude altimétrica (Figura 7d); desvio padrão altimétrico (Figura 7e); área de contribuição média (Figura 7f),declividade máxima (Figura 8a); e declividade média (Figura 8b). Além disso, foram calculados 
os seguintes parâmetros morfométricos: área (Figura 8c), perímetro (Figura 8d); índice de circularidade (Figura 8e).
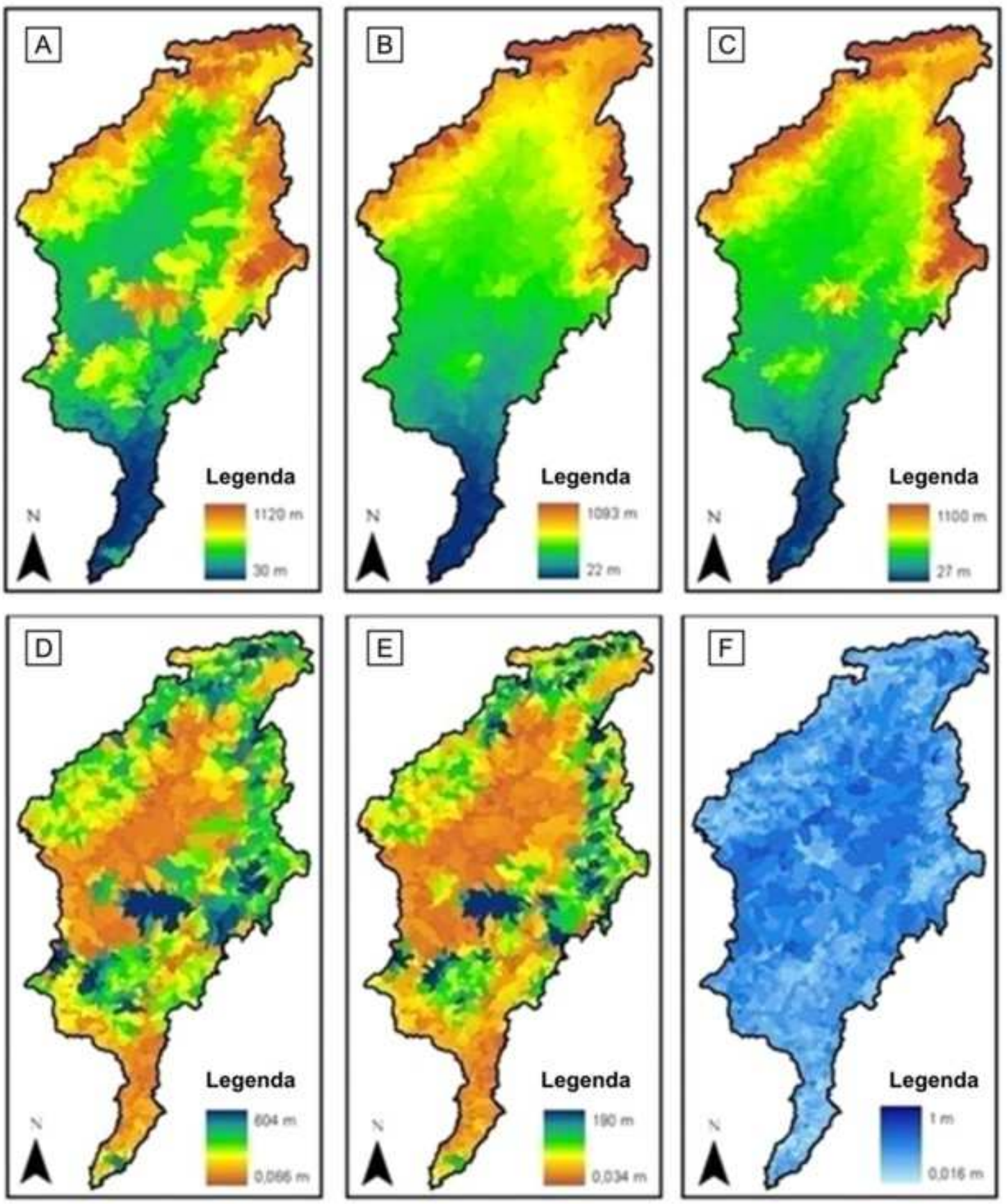

Figura 7. Atributos de terreno das bacias de $1^{\mathrm{a}}$ ordem: (a) altitude máxima; (b) altitude mínima; (c) altitude média; (d) amplitude; (e) desvio padrão; (f) área de contribuição média. 

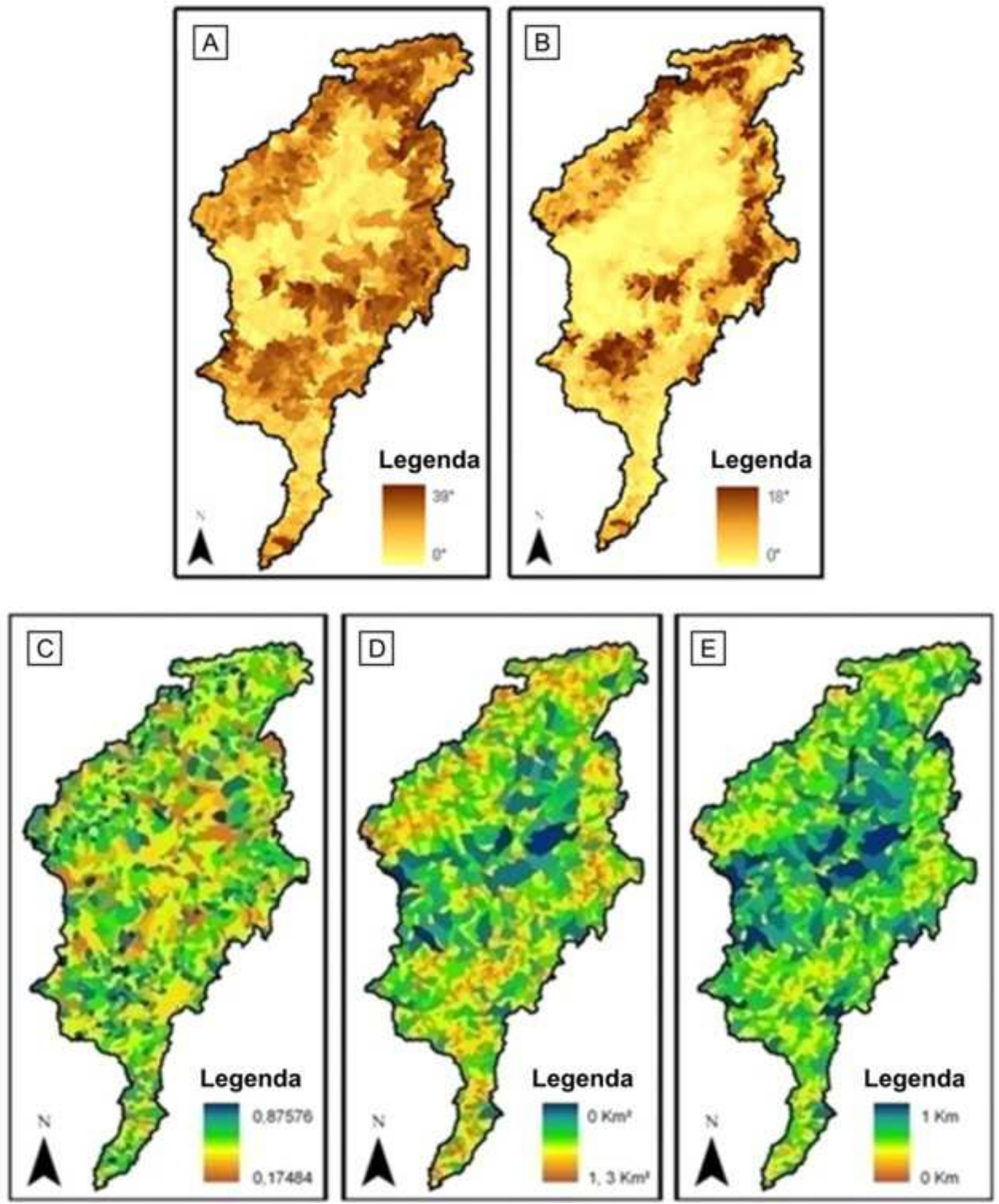

Figura 8.Atributos de terreno das bacias de $1^{\mathrm{a}}$ ordem: (a)declividade máxima; (b) declividade média;(c) índice de circularidade; (d) área; e (e) perímetro;.

Além dos atributos de terrenos amplamente utilizados (altimetria, declividade e área de contribuição) foi utilizada também a amplitude topográfica muito utilizada para estudos geomorfológicos com bacias hidrográficas (HADLEY e SCHUMM, 1961; MEIS et al., 1982; SILVA, 2002).

Geo UERJ - Ano 15, nº. 24, v. 2, $2^{\circ}$ semestre de 2013

ISSN: 1415-7543E-ISSN: 1981-9021

http://www.e-publicacoes.uerj.br/index.php/geouerj 


\section{c.Classificação das bacias de drenagem utilizando o método K-Médias}

Análise de clusters é um dos principais métodos estatísticos utilizados para agrupar dados pela homogeneidade existente. É utilizado, principalmente, na formulação de classificações e indicadores. Este método permite formular hipóteses sobre a distribuição interna dos dados possibilitando realizar uma análise exploratória das informações. A análise de grupos pode ser hierárquica ou não-hierárquica. Os procedimentos hierárquicos geram estruturas do tipo árvore, nas quais inicialmente cada elemento é um grupo e a cada passo, os dois grupos mais próximos são agrupados. Já os métodos não-hierárquicos servem para encontrar uma partição de $\mathrm{n}$ elementos em $\mathrm{k}$ grupos, satisfazendo dois requisitos: coesão interna e isolamento dos grupos (MINGOTI, 2007). Dentre os métodos não-hierárquicos um dos mais utilizados é o método K-Médias, primeiramente, descrito por Macqueen (1967). Este método caracteriza-se por assumir um número de grupo (k) fixo e um centro cujo valor é a sua média. A alocação dos membros para um determinado grupo é estabelecida de forma a minimizar uma função de erro (HARTIGAN e WONG, 1979). O método pode ser dividido em duas fases: (a) fase de inicialização, onde randomicamente são assinalados casos para os k grupos, e (b) fase de interação, o algoritmo computa a distância entre cada caso e cada grupo estabelece para o membro o grupo mais próximo. Muitas vezes o procedimento termina na determinação de um local ótimo (SELIM e ISMAIL, 1984).

No presente trabalho as bacias hidrográficas de $1^{\mathrm{a}}$ ordem são classificadas pelo método k-médias considerando suas variáveis morfométricas com a intenção de estabelecer grupos segundo critérios de proximidade, homogeneidade e heterogeneidade. Na classificação pelo método K-médias foi utilizado o programa SPlus. Testes utilizando combinações de variáveis foram realizados com o objetivo de encontrar o melhor ajuste que permitisse a análise geomorfológica.

\section{RESULTADOS}

A análise de grupos foi realizada considerando diferentes combinações de métricas. O melhor desempenho foi o que considerou todos os atributos resultando em sete classes(Figura 9).

Geo UERJ - Ano 15, n'. 24, v. 2, $2^{\circ}$ semestre de 2013

ISSN: 1415-7543E-ISSN: 1981-9021

http://www.e-publicacoes.uerj.br/index.php/geouerj 
Com base nas classes definidas pela análise de grupos foi feita uma aglutinação utilizando critérios de homogeneidade e heterogeneidade, bem como a relação dos polígonos encontrados com as feições da superfície de forma a obter quatro compartimentos denominados: Planalto da Borborema; Rebordos Escarpados e Elevações Residuais; Pediplano do Baixo São Francisco; e Depressão do São Francisco (Figura 10). As combinações com menor número de clusters resultaram em mapas com muitas generalizações e perda de informação, enquanto os mapas com maior número de clusters apresentaram redundâncias.

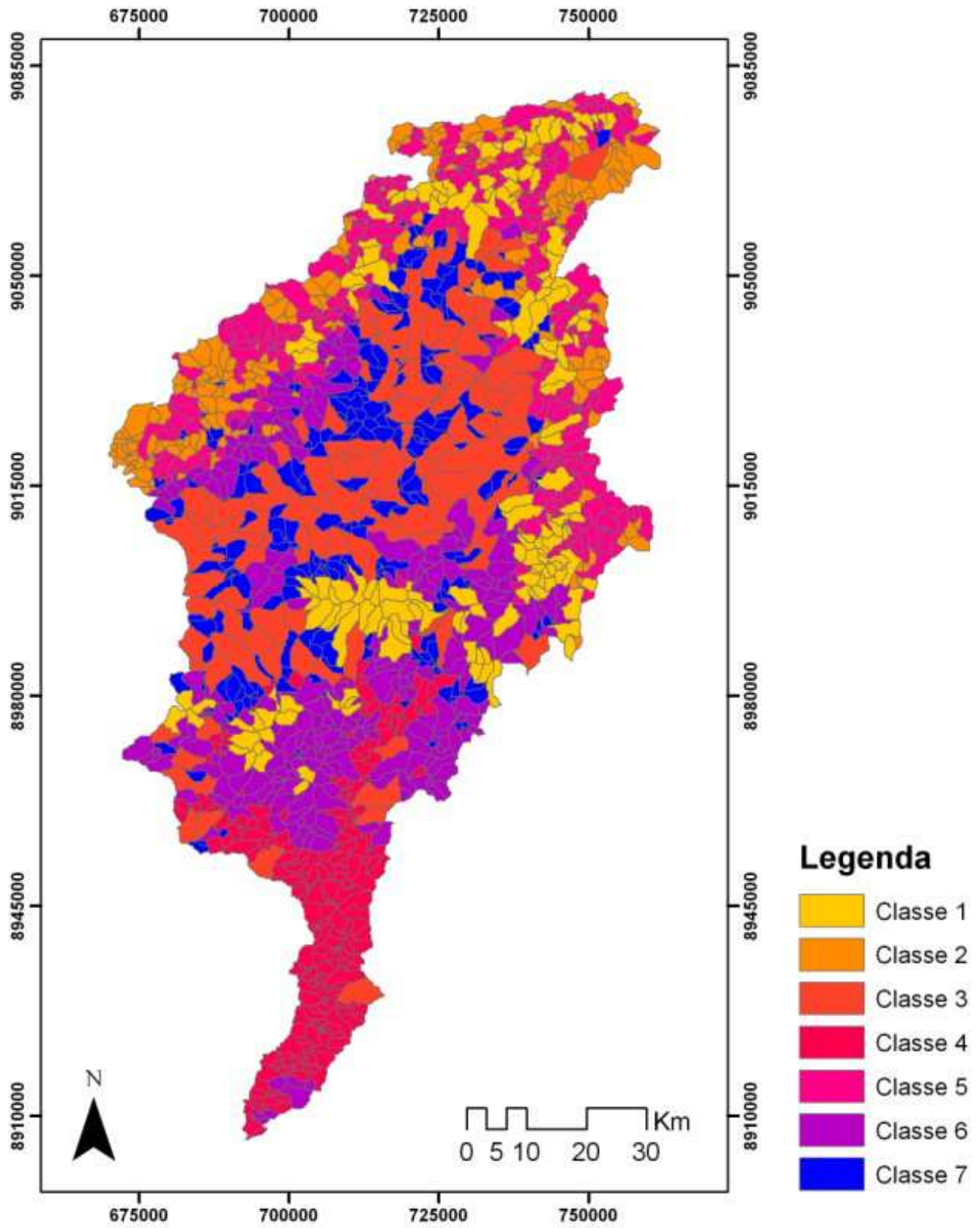

Geo UERJ - Ano 15, nº. 24, v. 2, $2^{\circ}$ semestre de 2013

ISSN: 1415-7543E-ISSN: 1981-9021

http://www.e-publicacoes.uerj.br/index.php/geouerj 
Figura 9. Análise de grupos utilizando todos os atributos de terreno.

As métricas de altimetria ajudaram a identificar todos os compartimentos devido ao alto grau de correlação desses atributos com a realidade. Os atributos de declividade acentuaram as áreas de encosta, porém, respondem mal à diferenciação das áreas mais planas.O mapa de área de contribuição possui uma boa capacidade de separação entre as áreas planas, ajudando a diferenciar, juntamente com os mapas de declividade e altimetria, aclasse dos Rebordos Escarpados e Elevações Residuais com relação à classe da Depressão do São Francisco.
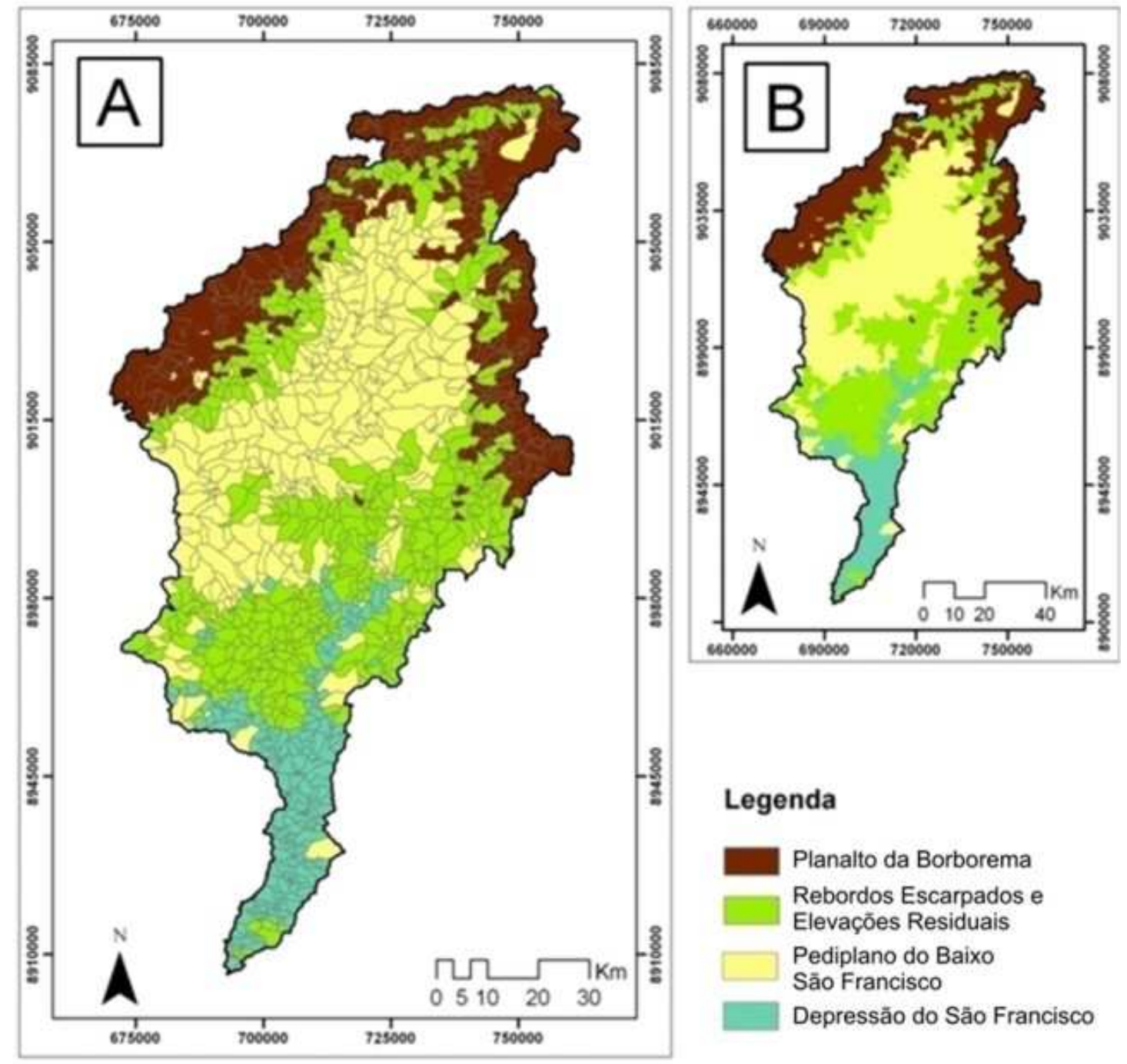

\section{Legenda}

Planalto da Borborema

Rebordos Escarpados e

Elevaçōes Residuais

Pediplano do Baixo

São Francisco

Depressão do São Francisco

Figura 10. Compartimentação geomorfológica da bacia do Ipanema, utilizando a análise de grupos, com (a) e sem (b)o limite das bacias. 
O Planalto da Borborema é formado por maciços e outeiros, com altitudes variando entre $1120 \mathrm{~m}$ e 900m dentro da bacia do Ipanema (Figura 11a). Esta unidade apresenta uma intensa atuação tectônica com reativação de dobramentos, fraturas e falhas e sucessivos aplainamentos, estendendo-se do estado do Alagoas até o Rio Grande do Norte (AB'SABER, 1953). Nesse compartimento surgem solos litólicos, com vários afloramentos onde o processo de degradação supera o de agradação. O clima predominante é seco com precipitação média da ordem de 400 a $650 \mathrm{~mm}$, onde predomina uma caatinga hipoxerófita (EMBRAPA, 2002).

Nos Rebordos Escarpados são representados por um relevo de alta declividade na qual predominam os processos de dissecação das vertentes que formam pequenos morros (Figura 12b). Os morros e morrotes que se formam na porção meridional da bacia resistem graças à formação rochosa mais resistente. A dissecação é controlada por linhas de falhas que perpassam a superfície em direções diferentes. Essa feição nada mais é do que a transição entre o topo (Planalto da Borborema)e a região de depressão (Pediplano do Baixo São Francisco). Neste compartimento o potencial erosivo é maior, devido à associação entre grandes declividades e a ação dos rios e da chuva.

O Pediplano do Baixo São Francisco caracteriza-se por vastos planos homogêneos combaixas declividades (média de 4 graus), formando uma depressão limitada pelos Rebordos Escarpados do Planalto da Borborema, que se abre para o leste. O pediplanose desenvolve em rochas pré-cambrianas, principalmente representadas por rochas metamórficas oriundas de sedimentos (Brasil, 1983).Nessa região a dinâmica de acumulação de sedimentos não é significativa visto que os solos predominantes são Regossolos, que apresentam um perfil raso e pedregoso. Neste compartimento nota-se a presença de pequenos inselbergs geralmente constituídos por granitóides que por diferenças de resistência à erosão tornam-se blocos residuais (Figura 12c).Estas feições residuais são classificadas conjuntamente com as áreas de encosta do Rebordo Escarpado devido suas semelhanças na movimentação topográfica.

A Depressão do São Francisco é representada na área pelo baixo curso do rio Ipanema adjacente ao Rio São Francisco (Figura 12d). As declividades são baixas e é caracterizada por ser uma superfície de pediplanação, onde formam vales, como o do rio Ipanema, que apresenta simetria nas margens em seu curso mais baixo. A monotonia 
nesse compartimento é cortada pelo surgimento de um relevo residual controlado por linhas de falha mais ao sul. A média pluviométrica anual dessa região é da ordem de $500 \mathrm{~mm}$. Os solos dessa região apresentam problemas de salinidade, devido à sazonalidade dos rios, sendo medianamente férteis (EMBRAPA, 2002).

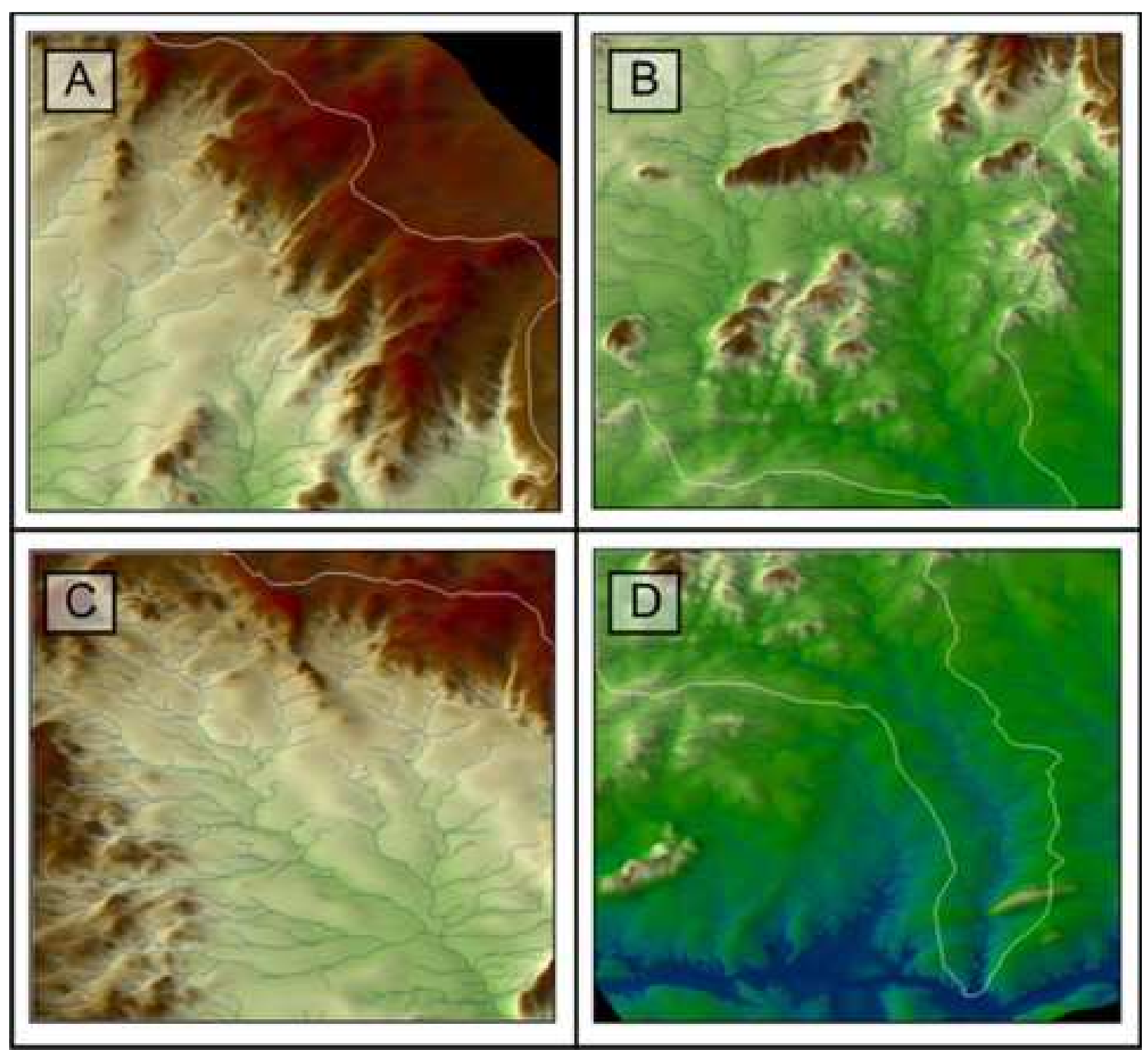

Figura 12. Visão tridimensional a partir do MDT das unidades geomorfológicas identificadas: (a) Planalto da Borborema, (b) Rebordos Escarpados, (c) Pediplano do Baixo São Francisco, e (d) Depressão do São Francisco.

\section{CONCLUSÕES}

As feições morfológicas das bacias de drenagem estão intrinsecamente correlacionadas com a auto-organização da natureza, onde a eficiência nos gastos energéticos explica a regularidade na geometria hidráulica, geomorfológica e da rede de 
drenagem (MOLNAR e RAMIREZ, 2002). O emprego de métodos computacionais e automáticos para obter e classificar as bacias de drenagem a partir de informações extraídos do MDT favorece a compreensão dos diferentes mecanismos de evolução que compõem a paisagem.

A análise de grupos a partir das características morfométricas das bacias de drenagem na bacia hidrográfica do rio Ipanema permite definir classes que apresentam condições semelhantes de formação. O método de classificação utilizado permite reduzir as subjetividades e obtém de forma rápida uma análise exploratória da bacia hidrográfica. O método utilizado é facilmente reproduzível, mas necessita de testes na definição dos parâmetros de entrada. Além disso, a acuidade do MDT e a densidade da rede de drenagem são fatores determinantes para a delimitação precisa das bacias de $1^{\text {a }}$ ordem.

As classes obtidas possuem relação com as feições naturais, permitindo definir compartimentos do relevo. Com os grupos encontrados a partir da análise multivariada foi possível distinguir as seguintes classes Planalto da Borborema; Rebordos Escarpados e Elevações Residuais; Pediplano do Baixo São Francisco; e Depressão do São Francisco. Desta forma, a metodologia mostrou resultados satisfatórios para subsidiar o planejamento ambiental na bacia do rio Ipanema. Os compartimentos demonstram um zoneamento que permite auxiliar o planejamento de uso e ocupação.

\section{REFERÊNCIAS BIBLIOGRÁFICAS}

AB'SABER, A. N. Os domínios de natureza no Brasil. $3^{\mathrm{a}}$ ed. Ateliê Editorial: São Paulo, 2005. 159 p.

AB'SABER, A. N. O planalto da Borborema na Paraíba. Boletim Paulista de Geografia, São Paulo, v. 13, p. 54-73, 1953.

BRASIL. MINISTÉRIO DAS MINAS E ENERGIA. SECRETARIA-GERAL. Projeto RADAMBRASIL Folhas SC. 24/25 Aracaju/Recife; geologia, geomorfologia, pedologia, vegetação e uso potencial da terra. Rio de Janeiro, 1983, 856 p.

CARDOSO, C.A.; DIAS, H.C.T.; SOARES, C.P.B. e MARTINS, S.V. Caracterização morfométrica da bacia hidrográfica do rio Debossan, Nova Friburgo, RJ. Revista Árvore, v. 30, n. 2,p. 241-248, 2006.

CPRM - SERVIÇO GEOLÓGICO DO BRASIL. Mapa de geologia do nordeste. Programa Geologia do Brasil. Recife: CPRM, 2004.

Geo UERJ - Ano 15, nº. 24, v. 2, $2^{\circ}$ semestre de 2013

ISSN: 1415-7543E-ISSN: 1981-9021

http://www.e-publicacoes.uerj.br/index.php/geouerj 
DEMATTÊ; J.A.M. e DEMÉTRIO, V.A. (1995) Fotointerpretação de padrões de drenagem de bacias hidrográficas na caracterização de solos desenvolvidos de rochas eruptivas básicas no estado do Paraná. Scientia Agricola, v. 52, n. 3, p. 567-577.

GILES, P.T.; FRANKLIN, S.E.An automated approach tothe classification of the slope units using digitaldata.Geomorphology, v. 21, p. 251-264,1998.

HADLEY, R.F.;SCHUMM, S.A. Sediment sources and drainage basin characteristics in Upper Cheyenne River basin.U.S. Geol. Survey Water-Supply Paper, v. 1531-B, p. 137-197, 1961.

HARTIGAN, P.; WONG, M. A. A k-means clusters ing algorithm: algorithm AS 1366. Applied Statistics, n.28, p. 126-130, 1979.

HUTCHINSON, M.F. A new procedure for gridding elevation and stream line data with automatic removal of spurious pits.Journal of Hydrology, v. 106, p. 211-232, 1989.

JENSON, S. K.; DOMINGUE, J. O. Extracting topographic structure from digital elevation data for geographical information system analysis.Photogrammetric Engineering\& Remote Sensing, v. 54, p. 1593-1600, 1987.

LANGBEIN, W.B. Geometry of river channels.JournalHydrautics Division American Society of Civil Engineers,v. 90 (HY2), p. 301-312,1964.

LANGBEIN, W.B.; LEOPOLD, L.B. Quasi-equilibriumstates in channel morphology.American Journal of Science, v. 262, p. 782-794, 1964.

MACQUEEN,E.Some methods for classification and analysis of multivariate observations. In: Proceedings of the 5th Berkeley Symposium on mathematical statistics and probability, v.1. p. 281-297. Berkeley, CA: UniversityofCalifornia Press. 1967.

MEIS, M.R.M.; MIRANDA, L.H.G.; FERNANDES, N.F. Desnivelamento de altitude como parâmetro para a compartimentação do relevo: bacia do médiobaixo Paraíba do Sul. In: Congresso Brasileiro de Geologia (CBG), 32., Salvador (BA). Anais... Salvador: Sociedade Brasileira de Geologia. 4: 1489- 1509. 1982.

MESA, L. M. Morphometric analysis of a subtropical Andean basin (Tucumán, Argentina).Environmental Geology, v. 50, p. 1235-1242, 2006.

MILIARESIS, G.; ARGIALAS, D. Segmentation ofphysiographic features from the global digitalelevation model/GTOPO30.ComputersandGeosciences, v. 25, n. 7, p. 715-728,1999.

MINGOTI, S. A. Análise de dados através de métodos de estatística multivariada: uma abordagem aplicada. Minas Gerais: EditoraUFMG, 2007.

MOLNAR, P.; RAMIREZ, J.A. On downstream hydraulic geometry and optimal energy expenditure: case study of the Ashley and Taieri Rivers. Journal of Hydrology, v. 259, p. 105-115, 2002. 
MONTGOMERY, D. R.; DIETRICH, W. E. Landscape dissection and drainage areaslope thresholds. In: Kirkby M. J. (Org.). Process Models and Theoretical Geomorphology.New York, 1994. p. 221-246.

O'CALLAGHAN, J.F. \& MARK, D.M. The extraction of drainage networks from digital elevation data. Computer vision, graphics, andimageprocessing, v. 28, p. 323344, 1984.

OLIVEIRA S. N.; CARVALHO JÚNIOR O. A.; SILVA, T. M.;GOMES, R.A.T.; MARTINS, E.S.; GUIMARÃES, R.F.; SILVA, N. C. Delimitação automática de bacias de drenagens e análise multivariada de atributos morfométricos usando modelo digital de elevação hidrologicamentecorrigido.RevistaBrasileira de Geomorfologia, v.8, n.1, p. 3-21, 2007.

REDDY, G.P.O.; MAJI, A.K.; GAJBHIYE K.S. Drainage morphometry and its influence on landform characteristics in a basaltic terrain, Central India - a remote sensing and GIS approach. International Journal of Applied Earth Observation and Geoinformation, v. 6,p. 1-16., 2004.

SANTOS, M. Por uma geografia nova: da crítica da geografia a geografia crítica. $6^{a}$ ed.EditoraEdusp: São Paulo, 2002, 285 p.

SELIM, S. \& ISMAIL, M. K-means-type algorithms for the clusters ing theorem and characterization of local optimality.IEEE Transactions on Pattern Analysis and Machine Intelligence, vol. 6, n.1, p. 81-87, 1984.

SILVA, T.M. A Estruturação Geomorfológica do Planalto Atlântico no Estado do Rio de Janeiro.265p. Tese (Doutorado em Geografia) -Departamento de Geografia IGEO/UFRJ, Rio deJaneiro.2002.

SODRÉ,R. V. R.; CARVALHO JÚNIOR, O.A.;MACHADO, W. P.; OLIVEIRA, S.N.;GOMES, R. A. T.; GUIMARÃES, R. F.; CARVALHO, A. P. F.; MARTINS, E. S. Classificação de bacias de drenagem do alto Jequitaí (Minas Gerais) a partir da análise de principais componentes e análise de grupos. Revista Brasileira de Geomorfologia, v. 8, n. 2 , p. $74-84,2007$.

SOUZA, A.K.P.S. e BATISTA, G.T. Caracterização fisiográfica da bacia hidrográfica do Alto Rio Jamanxim, Pará, Brasil. Revista Ambiente e Água, v. 2, n. 2, p. 69-87, 2007.

STRAHLER, A.N. (1952) Hypsometric (area-altitude) analysis and erosional topography.Bulletin of the Geological Society of America, v. 63 n. 10, p. 1117-1142.

TARBOTON, D. G.; BAKER, M. E. Towards an Algebra for Terrain-Based Flow Analysis.In:MOUNT, N. J.; HARVEY, G. L.; APLIN P.; PRIESTNALL,G. (Org.). Representing, Modeling and Visualizing the Natural Environment: Innovations in GIS 13, Florida:CRC Press,2008. p. 167-194.

TARBOTON, D. G. (1997) A New Method for the Determination of Flow Directions and Contributing Areas in Grid Digital Elevation Models.Water Resources Research, v. 33, n. 2, p. 309-319. 
VILLELA, S. M.; MATTOS, A. Hidrologia Aplicada. São Paulo: McGraw-Hill. 1975. $245 p$.

Artigo recebido para publicação em abril de 2013.

Artigo aceito para publicação em junho de 2013. 